\title{
Assessment of the therapeutic range of tiapride in patients with tardive dyskinesia
}

\author{
RAC ROOS,* EA VAN DER VELDE, $\ddagger$ OJS BURUMA,* FA DE WOLFF, Ph.D $\dagger$ \\ From the Department of Neurology, ${ }^{*}$ and Toxicology Laboratory, $\dagger$ University Hospital, and Department of \\ Medical Statistics, $\ddagger$ State University, Leiden, the Netherlands
}

SUMMARY Ten patients with tardive dyskinesia were treated with tiapride at an increasing dosage to establish the dose-concentration relationship and the dose-effect relationship. The effect was scored with the Abnormal Involuntary Movement Scale (AIMS) and the Doppler-radar method. The intra individual dosage-serum concentration correlation coefficients varied from 0.86 to 0.99 and the slopes of the individual regression lines varied from 0.16 to 0.58 . All patients showed a diminution of their involuntary movements during the treatment period. A negative correlation coefficient was found between the dosage of tiapride and the AIMS; range -0.22 till -0.93 , mean: $-0.65 \pm 0.23$ (SD). The Doppler-radar method results were inconclusive. No side-effects were observed.

Tiapride, a substituted benzamide, is used in clinical practice in several involuntary movement disorders with variable therapeutic effects. Beneficial effects, in some of the patients studied, are reported in tardive dyskinesia, ${ }^{1-6}$ Huntington's chorea ${ }^{237}$ and levodopa induced dyskinesia. ${ }^{2-4}$ However, no discrimination could be made between patients responding with a decrease of involuntary movements, the so-called responders, and the nonresponders. Studies in healthy young volunteers and in elderly patients ${ }^{8}$ showed that tiapride is rapidly absorbed after oral and intramuscular administration. The peak concentration is reached within two hours and the half life time of elimination is about 3.5 hours. ${ }^{910}$ Tiapride is mainly eliminated in unmetabolised form in the urine.

The first aim of this study was to establish the relationship between dosage and serum concentrations of tiapride in patients with tardive dyskinesia. The second aim was to find out whether a relationship exists between serum concentration and effect, namely a decrease of involuntary movements. In other words, to establish the therapeutic range for tiapride.

\section{Patients and methods}

Ten chronic schizophrenic patients, three males and seven

Address for reprint requests: Dr RAC Roos, Department of Neurology, University Hospital Leiden, Postbox 9600, 2300 RC Leiden, The Netherlands.

Received 2 July 1985 and in revised form 19 December 1985. Accepted 5 January 1986 females, with tardive dyskinesia were studied. Their mean age was 63.5 years (46-73 years). All patients stayed in a chronic care unit of a psychiatric hospital (Psychiatric Hospital Endegeest, Oegstgeest). Patients with diseases of the central nervous system, and patients with renal, hepatic or gastrointestinal diseases were excluded. All patients gave their informed consent and the study was approved by the Medical Ethics Committee of the University Hospital of Leiden. Previously prescribed medication was continued throughout the trial and had been unchanged for at least three months prior to the study. The prescribed medication included: promethazine, perphenazine, levomepromazine, flupenthixol, fluphenazine, haloperidol, pimozide, bromperidol, lorazepam, orphenadrine, amantadine, amitriptyline, carbamazepine and phenobarbitone. All patients started with three daily dosages of $100 \mathrm{mg}$ tiapride for one week at $08.00 \mathrm{hrs}, 15.00 \mathrm{hrs}$, and $22.00 \mathrm{hr}$. On the seventh day a serum concentration-time curve in blood was obtained. The dosage was increased (fig 1) up to a maximum

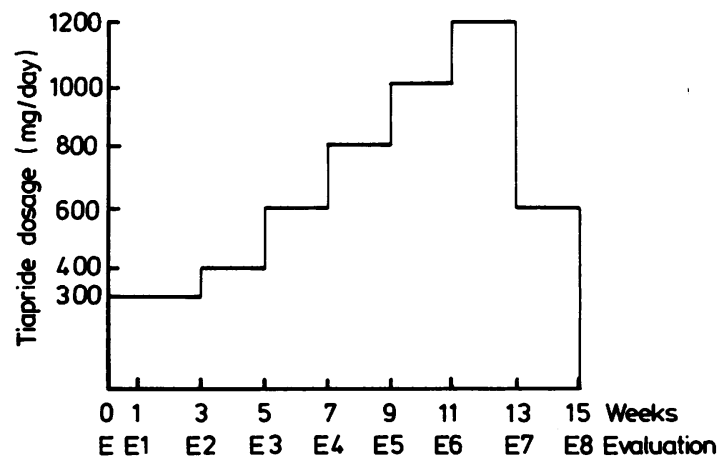

Fig 1 Scheme of protocol; $E$ = evaluation. 
of $1200 \mathrm{mg}$ daily. Evaluations took place after one week, and subsequently every fortnight. Each evaluation lasted about two hours and consisted of the following examinations. Involuntary movements were rated with the Abnormal Involuntary Movement Scale (AIMS) ${ }^{11}$ by two examiners independently, the mean score was used. The amount of orofacial involuntary movements was also measured by means of a Doppler-radar device. ${ }^{12}$ The mean value of two one-minute scores was taken. A three point self-assessment scale was filled in by the patients. Blood samples were taken just before the morning dose of tiapride $\left(\mathrm{t}_{0}\right)$, and after two hours $\left(t_{2}\right)$. The serum was stored at $-20^{\circ} \mathrm{C}$ until analysed with a SP-HPLC method. The assay method for the tiapride determination is the following: to $200 \mu \mathrm{l}$ of either patients' serum or standard sera spiked with $0-4.0 \mu \mathrm{g} / \mathrm{ml}$ tiapride are added respectively $50 \mu \mathrm{l} \mathrm{NaoH} 1.5 \mathrm{~mol} / 1,200 \mu$ linternal standard ( $\mathrm{N}$-propionylprocainamide $10 \mu \mathrm{g} / \mathrm{ml}$ in dichloromethane) and $7 \mathrm{ml}$ dichloromethane. After 10 minutes mixing and 5 minutes centrifuging the upper layer is discarded and the organic layer is evaporated until dryness at $45^{\circ} \mathrm{C}$ under nitrogen. The residue is dissolved in $50 \mu$ l eluent

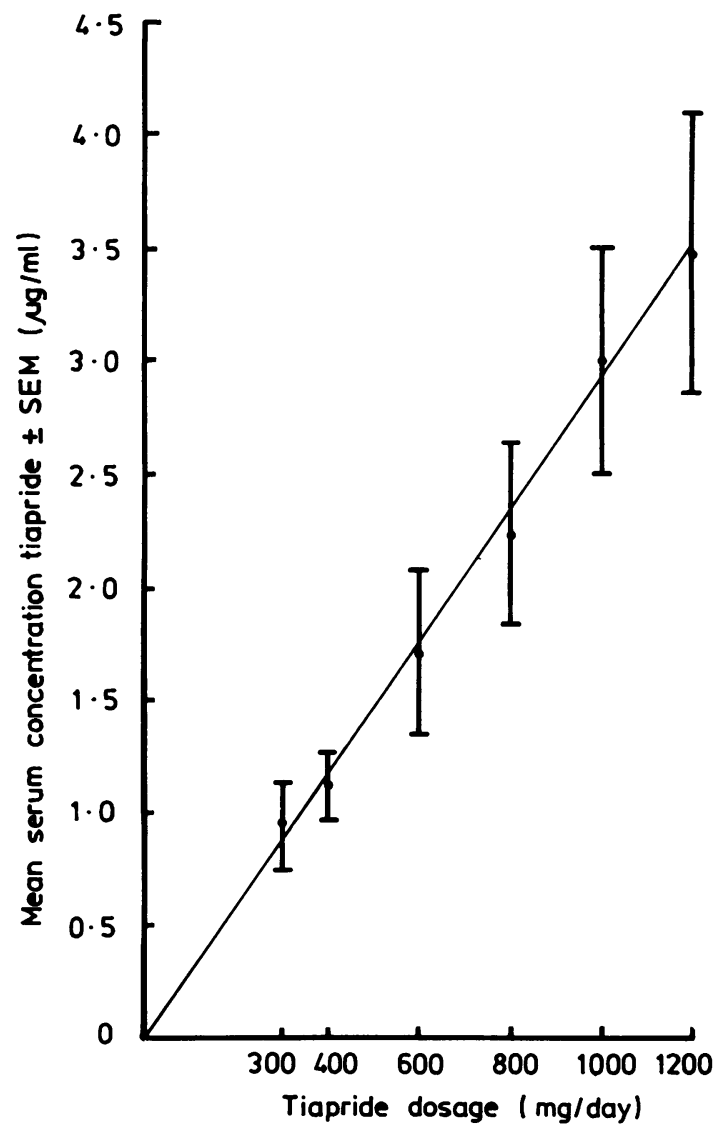

Fig 2 Dosage of tiapride versus mean serum concentrations ( $\pm S E M)$ for nine patients with tardive dyskinesia. The mean slope of regression is also given (0.30). of which $20 \mu \mathrm{l}$ is injected into an HPLC equipped with an UV detector operating at $230 \mathrm{~nm}$. The column is a $100 \times 3$ mm Lichrosorb Si $605 \mu \mathrm{m}$; the eluent is composed of acetonitrile 250 , methanol 55 , ammonium hydroxide $(1 \mathrm{~mol} / \mathrm{l})$ 13. Flow rate is $0.8-1.0 \mu \mathrm{l} / \mathrm{min}$. Details of this method will be published elsewhere. Serum creatinine and gamma-GT were determined as parameters for renal and liver function, respectively.

\section{Results}

Three weeks after the start of the trial one patient became psychotic and had to be excluded. Tiapride was discontinued immediately without any effect on the psychosis. The patient did not respond to changes in his neuroleptic drugs for the first month. One other patient was withdrawn after seven weeks because of an epileptic fit. The serum levels of carbamazepine and phenobarbital were within the therapeutic range

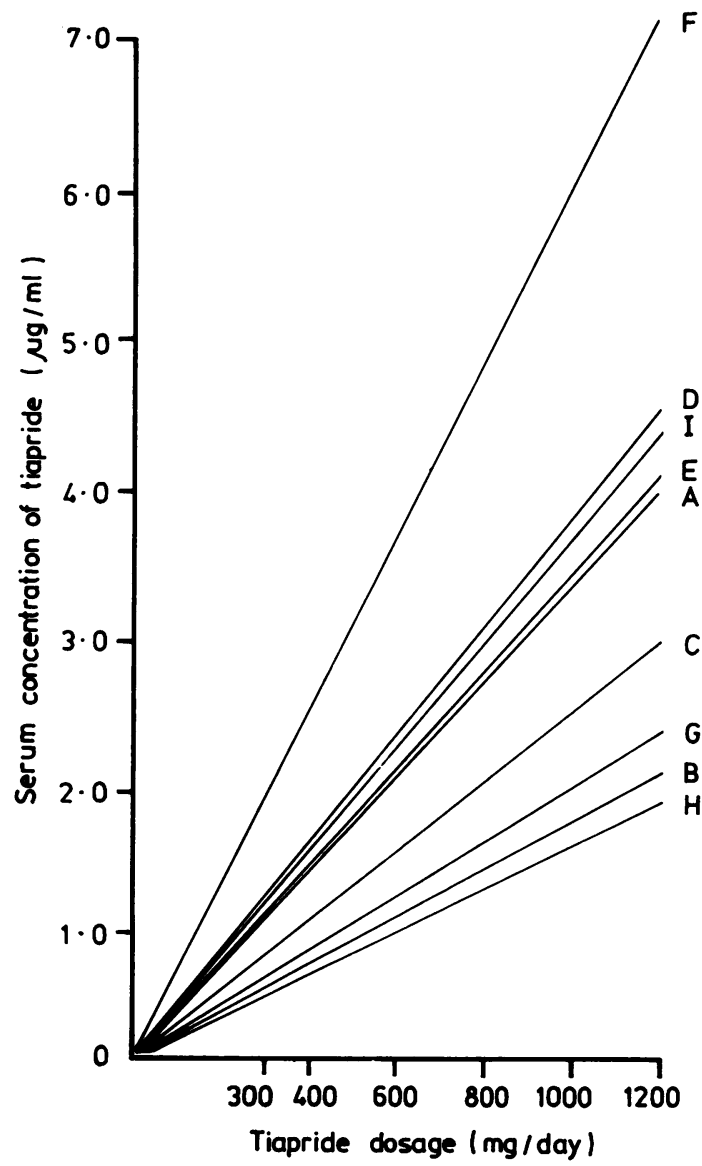

Fig 3 Regression lines of dosage of tiapride and serum concentration in nine patients with tardive dyskinesia. 


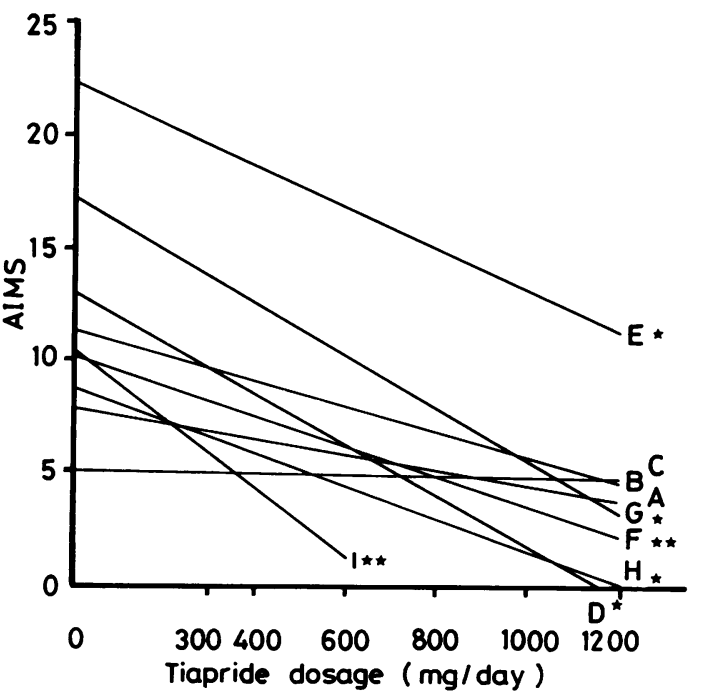

Fig 4 Regression lines of dosage of tiapride versus AIMS-score (effect) in nine patients with tardive dyskinesia. ${ }^{*} D, E, G$ and $H: p<0.05$.

${ }^{* *} F: p=0.054 ; I: p=0.053$.

not significant: $A, B$, and $C$.

and unchanged as compared to levels prior to the start of the trial. The results of this patient are included for as long as she stayed in the trial.

The mean $( \pm$ SEM) serum concentrations of tiapride $\left(t_{2}\right)$ for the dosages used in this trial are plotted in fig 2 . For each patient a linear relationship was found between the daily dosage and the serum concentration. The intra-individual correlation coefficient varied from 0.86 to 0.99 with a mean value 0.94 . The regression lines (with intercept $=0$ ) are given in fig 3. Rather large differences were found between the individual lines of the patients.

All patients showed a decrease in the amount of involuntary movements, as indicated by a lower AIMS-score, after the start of the trial. One patient only responded a little, even on higher dosages. A negative correlation was therefore found for all patients between the daily dosage of tiapride and the AIMS-score. The correlation-coefficient ranged from -0.22 to -0.93 . The regression lines are shown in fig 4. The correlation coefficient between the serum concentration of tiapride and the AIMS-score ranged from +0.22 to -0.93 . Half-way through the trial the location for the Doppler-radar method measurements had to be changed twice, therefore results with the Doppler-radar method appeared to be too inconsistent to draw any conclusions. The self-assessment scales appeared to be useless, because of the inconsistent responses given. No side-effects and in particular no hypokinetic-rigid symptoms were observed. The serum creatinine and gamma-GT remained within normal limits throughout the study.

\section{Discussion}

The beneficial effect of tiapride in tardive dyskinesia has been reported in one double-blind cross-over clinical trial of four weeks and with a doses up to $300 \mathrm{mg}$ tiapride daily ${ }^{1}$ and in several open trials. ${ }^{2-4}$ Because the optimum dose and long term effects of tiapride are still largely unknown this study of longer duration and with increasing dosage was undertaken. Both the positive correlation between dosage and blood levels of tiapride and the negative correlation between tiapride dosage and AIMS-score showed that an increase of dosage above $\mathbf{3 0 0} \mathrm{mg}$ daily results in a further reduction of involuntary movements. The maximum response, namely a total absence of involuntary movements, was not reached. These results leave the question unanswered whether a dosage exceeding $1200 \mathrm{mg}$ tiapride daily, will result in still further diminution of involuntary movements.

In summary, we found a linear relationship between dosage of tiapride and serum concentration in the individual patient. Because of the large interindividual differences in dose-concentration relationships it might be useful to determine the tiapride serum concentration in the initial period of treatment in each patient. Tiapride diminished the involuntary movements more effectively in higher dosages, and during longer periods of treatment. We could not establish an upper limit for the therapeutic concentration of tiapride. Dosages up to $1200 \mathrm{mg}$ daily were tolerated without any side effects. Whether tiapride diminishes involuntary movements without itself inducing them after longer periods of treatment cannot be concluded from this study. However, no reports of the induction of involuntary movements by tiapride in man have yet been published.

We thank JG Goekoop MD for the Psychiatric Hospital Endegeest, Oegstgeest for his help in selecting the patients. J van de Nes MD is thanked for his assistance. Mr EJM de Haas determined the serum concentrations of tiapride. DelaGrange supplied the tiapride. Miss A Koetsier and Mrs KN WagensveldHansen typed the manuscript.

\section{References}

${ }^{1}$ Buruma OJS, Roos RAC, Bruyn GW, Kemp B, Velde EA. v.d. Tiapride in the treatment of tardive dyskinesia. Acta Neurol Scand 1982;65:38-44.

${ }^{2}$ Chouza C, Romero S, Lorenzo J, et al. Traitement des dyskinésies par le tiapride. Sem Hôp Paris 1982;58: 725-33.

${ }^{3}$ Lipcsey A, Nagy E. Expérience clinique du tiapride en 
neurologie. Sem Hôp Paris 1982;58:867-71.

${ }^{4}$ Miletto G, Julou M. Le tiapride en neurologie et en psychiatrie chez la personne âgée. Sem Hôp Paris 1981;57:1833-6.

${ }^{5}$ Rust M. Anwendung von Tiaprid bei persistierenden spätdyskinesien als Folge einer Neuroleptika Behandlung. Müch Med W Schr 1983;125:461-2.

${ }^{6}$ Pollak P, Gaio JM, Hommel M, Pellat J, Perret J. Effects of tiapride in tardive dyskinesia. Psychopharmacology 1985;85:236-9.

${ }^{7}$ Roos RAC, Buruma OJS, Bruyn GW, Kemp B, Velde EA. v.d. Tiapride in the treatment of Huntington's chorea. Acta Neurol Scand 1982;65:45-50.

${ }^{8}$ Roos RAC, Haas EJM de, Buruma OJS, Wolff EA de. Pharmacokinetics of tiapride in patients with tardive dyskinesia and Huntington's disease. Eur J Clin Phar- macol (In press).

${ }^{9}$ Rey E, Athis Ph.D, Richard MO, Lauture D de, Olive G. Pharmacokinetics of tiapride and absolute bioavailability of three extravascular forms. Int J Clin Pharmacol Ther Toxicol 1982;20:62-7.

${ }^{10}$ Strolin-Benedetti M, Donath A, Frigerio A, Morgan KT, Lavelle C, Malnoe A. Absorption, élimination et métabolisme du tiapride, (FLO, 1347), médicament neuroleptique, cheze le rat, le chien et l'homme. Ann Pharmaceut Franc 1978;36:279-88.

${ }^{11}$ AIMS: In: ECDEV Assessment Manual, ed: Guy W. Rockville Maryland, US Dept Health Education and Welfare 1976:534-7.

${ }^{12}$ Buruma OJS, Kemp B, Roos RAC, Fransen JM. Quantification of choreatic movements by Dopplerradar. Acta Neurol Scand 1982;66:363-8. 